\title{
Vetores selváticos de doença de Chagas na área urbana de Manaus (AM): atividade de vôo nas estações secas e chuvosas
}

Chagas' disease wild vectors in the urban area of Manaus,

State of Amazonas, Brazil: flight activities in dry and rainy seasons

Maricleide de F. Naiff, Roberto D. Naiff e Toby V. Barrett

Resumo Adultos de Rhodnius prolixus, R. pictipes e Panstrongylus geniculatus encontrados em casas em Manaus apresentam altas taxas de infecção por Trypanosoma cruzi. Rhodnius spp não apresentavam sazonalidade acentuada, porém os encontros de machos de P. geniculatus eram muito mais freqüentes na estação seca.

Palavras-chaves: Triatominae. Dispersão. Ecologia urbana.

Abstract Adults of Rhodnius prolixus, R. pictipes and Panstrongylus geniculatus found in houses in Manaus have high rates of Trypanosoma cruzi infection. Rhodnius spp. were found throughout the year, but males of $\mathrm{P}$. geniculatus were significantly more frequent in the dry season.

Key-words: Triatominae. Dispersal. Urban ecology.

Instituto Nacional de Pesquisas da Amazônia - INPA, Coordenação de Pesquisas em Ciências da Saúde.

Endereçeo para correspondência: Dr ${ }^{\mathrm{a}}$ Maricleide de Farias Naiff. INPA/CPCS-Caixa Postal 478, 69011-970 Manaus, AM, Brasil. FAX: (092) 643-3061.

Recebido para publicação em 18/07/97. 
Embora tenha-se conhecimento de apenas um caso autóctone de tripanosomiase humana em Manaus, é comum o encontro de triatomíneos adultos, infectados com Trypanosoma cruzi, em residências na área metropolitana. Durante 14 anos, entre 1980 e 1993, foram mantidos registros dos triatomíneos entregues espontaneamente ao nosso laboratório, por membros do público e servidores do INPA, interessados em obter identificação dos "barbeiros" e orientação sobre os riscos de doença de Chagas. Em alguns casos, o risco aparente não era trivial, com a apresentação de insetos infectados amassados, alimentados, e/ou encontrados de manhã na rede de dormir ou embaixo da cama. Com o objetivo de avaliar a distribuição dos registros durante 0 ano, estes foram agrupados em quadrimestres correspondendo à estação "seca" e à primeira e segunda metade da estação chuvosa (Tabela 1). O quadrimestre menos chuvoso nos anos 1980-1993 normalmente foi junho-setembro ou julho-outubro, com o início do período de chuvas mais pesadas ocorrendo em torno de novembro e seu final em maio ou junho. O tamanho das amostras de triatomíneos não foi suficiente para justificar comparações entre meses ou anos individuais.

Apenas triatomíneos adultos, de três espécies, foram coletados em casas em Manaus, não havendo nenhum indício de colonização. A população de Rhodnius prolixus em Manaus tem sido designada também como $R$. robustus 3 , mas esta espécie não é bem definida taxonomicamente. A população de Manaus é, de fato, cromaticamente e morfometricamente distinta do vetor envolvido no ciclo domiciliar de transmissão de doença de Chagas na América Central, e essas duas populações são apenas parcialmente inter-férteis em cruzamentos experiementais ${ }^{1}$. Além disso, as casas em Manaus não apresentam características como cobertura de palha de palmeira ou paredes de taipa, normalmente associadas com as infestações por $R$. prolixus nas áreas endêmicas.

Entre os triatomíneos examinados, 19/21 Panstrongylus geniculatus, 15/21 $R$. prolixus e

Tabela 1 - Número de triatomíneos adultos entregues, por espécie, sexo e época do ano; INPA - Manaus, 1980 -1993.

\begin{tabular}{|c|c|c|c|c|c|c|c|c|}
\hline \multirow[t]{2}{*}{$\begin{array}{l}\text { Espécie/estação } \\
\text { /ppt.* }\end{array}$} & \multicolumn{2}{|c|}{$\begin{array}{l}\text { Mar-jun } \\
(229,5)\end{array}$} & \multicolumn{2}{|c|}{$\begin{array}{l}\text { Jul-out } \\
(121,6)\end{array}$} & \multicolumn{2}{|c|}{$\begin{array}{l}\text { Nov-fev } \\
(246,0)\end{array}$} & \multicolumn{2}{|c|}{$\begin{array}{c}\text { Total } \\
(2,388)^{\star *}\end{array}$} \\
\hline & $\mathrm{M}$ & $\mathrm{F}$ & $M$ & $\mathrm{~F}$ & $M$ & $\mathrm{~F}$ & $\mathrm{M}$ & $\mathrm{F}$ \\
\hline P. geniculatus & 1 & 0 & 13 & 3 & 1 & 5 & 15 & 8 \\
\hline R. prolixus & 1 & 4 & 2 & 2 & 6 & 6 & 9 & 12 \\
\hline R. pictipes & 11 & 3 & 6 & 3 & 4 & 5 & 21 & 11 \\
\hline
\end{tabular}

* Média mensal no quadrimestre ${ }^{* *}$ média anual de precipitação em mm, obtidas na estação climatológica da Reserva Florestal Adolpho Ducke, Manaus, no período de 1980-1993. M = masculino; $F=$ feminino.

Fonte: CPGC-INPA.

20/29 R. pictipes apresentaram flagelados no intestino, identificados como T. cruzi, confirmado na maioria dos casos, por inoculação em camundongos. Dois $R$. prolixus apresentaram flagelados identificados como $T$. rangeli nas fezes e um deles transmitiu o parasita a camundongo, por picada. Um R. pictipes apresentou T. rangeli nas fezes, confirmado por inóculo em camundongos.

A razão de machos para fêmeas foi de quase 2:1 para $P$. geniculatus e $R$. pictipes, sendo mais equilibrada para $R$. prolixus (Tabela 1). O número de registros por quadrimestre sugere que a dispersão por vôo de machos de $P$. geniculatus ocorre principalmente na estação mais seca $(13 / 15$, chi-quadrado $=19,2$; $P<0.0001)$. Há indício que as fêmeas de $P$. geniculatus voam mais no final do período mais seco ou início do período chuvoso. Registros de $R$. prolixus e $R$. pictipes foram um pouco mais freqüêntes no início e final, respectivamente, no período chuvoso. Somando as espécies, os totais de triatomíneos registrados por quadrimestre apresentaram distribuição quase uniforme ao longo do ano.

A palmeira inajá Attalea maripa (Aubl.) Mart. (= Maximiliana regia Mart.) se desenvolve bem em vegetação secundária e áreas desmatadas2 e em Manaus chega a ser elemento marcante da paisagem suburbana nos terrenos baixos não inundáveis, inclusive nos quintais das casas. As bases dos pecíolos persistem no caule após a queda das folhas velhas, formando um refúgio onde roedores e marsupiais como Didelphis marsupialis e outros hospedeiros de T. cruzi constroem seus ninhos. A. maripa é 
conhecida como ecótopo importante para $R$. prolixus e $R$. pictipes em Manaus ${ }^{3}$ e sua persistência em vegetação perturbada contribui para manutenção de ciclos enzoóticos de transmissão de $T$. cruzi e $T$. rangeli dentro do perímetro urbano.

\section{REFERÊNCIAS BIBLIOGRÁFICAS}

1. Barrett TV. Species interfertility and crossing experiments in Triatomine systematics. In: Schofield CJ, Dujardin JP, Jurberg $\mathrm{J}$ (eds) Proceedings of the International Workshop on Population Genetics and Control of Triatominae, Santo Domingo de los Colorados, Ecuador. INDRE, Mexico City, p. 72-77, 1996.

2. Henderson A, Galeano G, Bernal R. Field Guide to the Palms of the Americas. Princeton University Press, New Jersey, p. 162, 1995.
3. Miles MA, Arias JR, Souza AA. Chagas' disease in the Amazon Basin: V. Periurban palms as habitats of Rhodnius robustus and Rhodnius pictipes Triatomine vectors of Chagas' disease. Memórias do Instituto Oswaldo Cruz 78:391-398, 1983. 